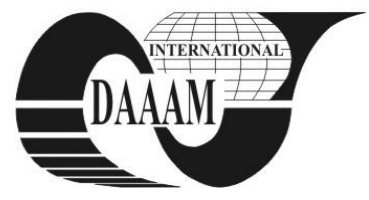

Annals of DAAAM for 2011 \& Proceedings of the 22nd International DAAAM Symposium, Volume 22, No. 1, ISSN 1726-9679 ISBN 978-3-901509-83-4, Editor B. Katalinic, Published by DAAAM International, Vienna, Austria, EU, 2011 Make Harmony between Technology and Nature, and Your Mind will Fly Free as a Bird Annals \& Proceedings of DAAAM International 2011

\title{
ULTRASONIC MEASUREMENT BASED MODELLING OF CHILLED CAST IRON THERMO ROLL
}

\section{WIDMAIER, T[homas] V[altteri] E[rnst]; PIRTTINIEMI, J[ukka] T[apio]; KIVILUOMA, P[anu] J[uhani]; PORKKA, E[sa] A[slak] \& KUOSMANEN, P[etri] O[lavi]}

\begin{abstract}
This paper discusses the creation of a model which can be used to analyse the behaviour of a chilled cast iron thermo roll at different operating conditions. In order to acquire additional information about the internal structure of the roll shell ultrasonic measurements of a full size roll were carried out. The created roll model's shapes and dimension correspond well to general knowledge about the chilled cast iron thermo rolls

Key words: paper machine, calender, thermal deformation, peripheral bore, calender
\end{abstract}

\section{INTRODUCTION}

For many decades the chilled cast iron thermo rolls have been successfully used in calenders of paper machines. The roll body is cast in a stackable chill mould usually with a sand core. The casting and manufacturing process of the chilled cast thermo rolls is discussed in detail in the dissertation (Maijer, 1998). The thickness and the microstructure of the roll shell is a function of temperature and time during the casting and cooling process (Maijer, 1998; Jackot et al., 2000; Seah et al., 1998). The outer surface layer consists mainly of white iron. Moving toward the inner diameter, the microstructure shifts to that of an equilibrium grey iron microstructure. The microstructure in the transition zone is referred to as being mottled, thus named as mottle iron. The layers do not have a clear boundary.

The working principle of thermo rolls is based on hot heating fluid flowing through the roll body in peripherally drilled bores. The drilling is normally performed from both ends of the roll body and the bores meet in the middle of the roll. Small meeting errors are common. The sag of the boring rod together with the inhomogeneous material in the roll body causes also variation in the axial depths of the passages. This variation may cause an uneven temperature distribution and thermal deformations in the roll. In addition the uneven mass distribution may cause unbalance in the roll. When the heating fluid flows in the passages it releases some of its heat to the roll and cools down. This causes a temperature drop between the beginning and the end of the passage. (Wirtz, 2002; Rothenbacher \& Vomhoff, 1985; Zaoralek, 2004)

The layers in the roll shell have a different iron phase, thus having different material values, i.e. hardness, thermal conductance, coefficients of thermal expansion, density and elastic modulus. The layers can also have an asymmetrical arrangement because of their varying thickness. When such a roll is heated it can deflect like a bi-metal rod. Other thermal deformations are also possible. Because of these deformations, a thermo roll that has practically no run-out at room temperature may have a significant run-out at the operating temperature in the paper machine (Rothenbacher \& Vomhoff, 1985; Wirtz, 2002; Brierley et al., 1977).

This work discusses the creation of a model to study the behaviour of a chilled cast iron thermo roll. Ultrasonic measurements are used to measure the layer thickness of the white iron layer on the roll surface and to acquire dimensions of the peripherally drilled bores in the shell of the roll body. These dimensions are not measurable by normal work shop measuring devices. The focus of this study is on the peripherally drilled chilled cast iron thermo rolls, but some of the results can be extended to other roll types too.

\section{METHODS}

\subsection{Thermo roll}

In this study a chilled cast iron thermo roll was used as a basis for a roll model. The thermo roll was the upper roll of an online soft calender (Fig. 1). The lower roll is a deflection compensated soft coated roll. The calender is used to improve the properties of the paper web by pressing and heating. The dimensions of the thermo roll are given in Table 1 . The heating fluid of the thermo roll was thermal oil.

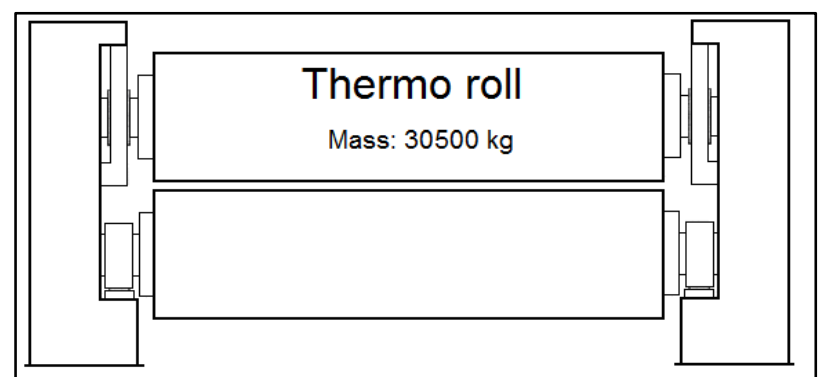

Fig. 1. The studied thermo roll is the upper roll of a soft calendar

\begin{tabular}{|l|r|}
\hline Total length & $9810 \mathrm{~mm}$ \\
\hline Body length & $7690 \mathrm{~mm}$ \\
\hline Max. paper web width & $6660 \mathrm{~mm}$ \\
\hline Nominal diameter & $1067 \mathrm{~mm}$ \\
\hline Shell thickness of the roll body & $198 \mathrm{~mm}$ \\
\hline Bearing length & $8400 \mathrm{~mm}$ \\
\hline Number of peripheral bores & 40 \\
\hline Diameter of peripheral bores & $\phi 32 \mathrm{~mm}$ \\
\hline Layer thickness of white iron & $9 \mathrm{~mm}$ \\
\hline Layer thickness of mottle iron & $42 \mathrm{~mm}$ \\
\hline
\end{tabular}

Tab. 1. Test roll dimensions

The test roll was measured with the ultrasound measuring device during maintenance. The ultrasonic measurements were carried out at a roll shop on a roll grinder. The measurements were done with a developed ultrasonic measuring device.

\subsection{Ultrasonic measurements}

The ultrasonic wall thickness measurement is based on the measurement of time of flight of ultrasonic pulse echoes created at the interfaces, e.g. outer and inner surface of a tube. The speed of sound has a different value in the different layers of cast iron, thus making the normal ultrasonic shell thickness measurement difficult. Because the shell thickness of the body of the thermo roll is normally known, the variation in the ultrasonic thickness measurement can be used to estimate the 
layer thickness distribution, if the speeds of sound in the different layers are known.

It was assumed that one half of the mottle iron layer behaves like grey iron and the other half like white iron, so the roll could be treated like an object with two layers. The locations of the centrelines of the peripheral bores in the roll were measured with the same ultrasonic measurement device.

\subsection{The model of the thermo roll}

The roll model was based on the dimensions of the test thermo roll. The model was completed with the dimensions of the peripheral bores and the layer thickness of white iron measured with ultrasound. The model was created with Pro/Engineer CAD software. This 3D model can be exported to other software, e.g. for simulation.

\section{RESULTS}

\subsection{Layer border}

The average thickness of the roll shell was $184.9 \mathrm{~mm}$ and the maximum deviation from the average was $\pm 2.0 \mathrm{~mm}$. The layer distribution was calculated with computer software and the result is presented in Fig. 2. The thickness variation of the white iron layer was between $27.0 \mathrm{~mm}$ and $33.3 \mathrm{~mm}$.

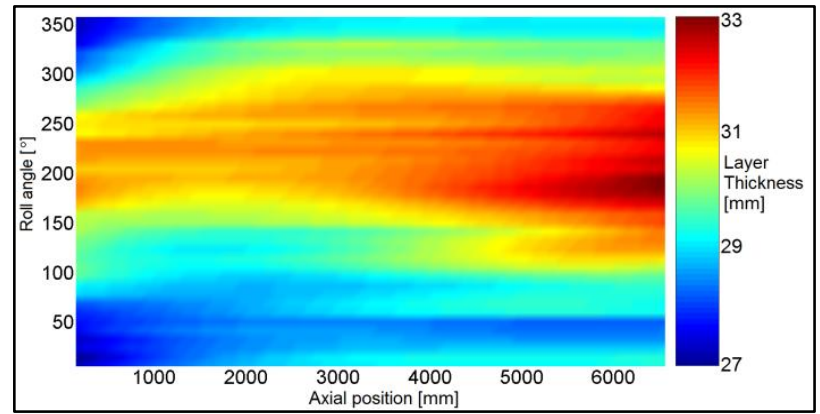

Fig. 2. The layer thickness map created from the measured ultrasonic shell thickness data

\subsection{Peripheral bores}

The depths of the peripheral bores with the best and worst meeting are presented in Fig. 3. The model for the bores was created based on the depth data of the bores. The depth value is the distance of the centreline of the peripheral bore from the surface.

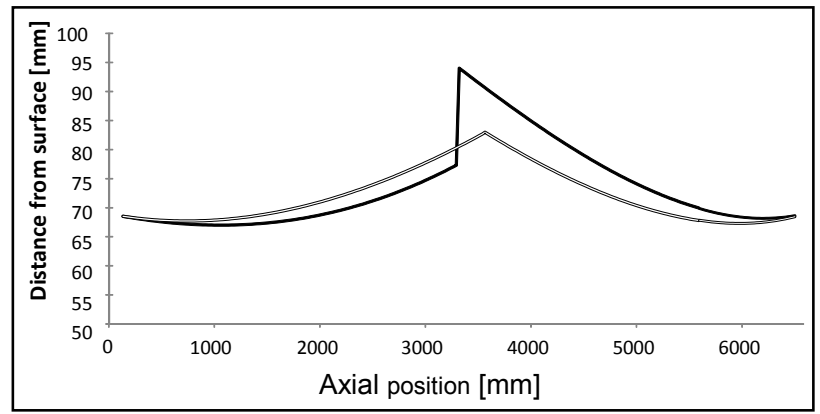

Fig. 3. Bore depths of the bores with the best and the worst meeting in the roll body

\subsection{The roll body model}

The layer thickness data was converted to a surface model. From the surface two solids was created. The surface became the inner surface of the white iron solid and the outer surface of the grey iron solid.

From the bore data the centrelines of the bores were created. Each centreline was used as the trajectory of a protrusion. The protruded section was a circle with the diameter of $32 \mathrm{~mm}$. The created solid with 40 protrusions (Fig. 4.) was used to cut the peripheral bores into the grey iron solid. The roll body model was ready, when the white and grey iron models were combined.

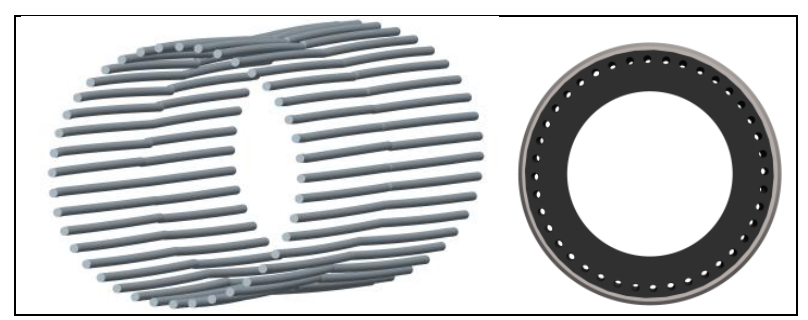

Fig. 4. The cut-out bore model and the roll body model

\section{CONCLUSION}

The ultrasonic measurement makes it possible to model the behaviour of a chilled cast thermo roll with a precision not seen before. In addition to the technical drawings and specifications, the real microstructure and effects caused by manufacturing process can be taken into account. The structure, shape and dimension of the created roll model correspond well to general knowledge about the chilled cast iron thermo rolls. The validation of the measured dimensions, however, is challenging, because the only known method to verify them (especially the layer thicknesses), is to slice the roll and analyse and measure these pieces. The roll cannot be fitted inside an Xray or another non-destructive measuring device. None of the current thermo roll owners is probably willing to scrap their roll for the interest of science. Smaller test rolls and/or co-operation with the roll manufacturer can provide a solution to this problem. Also a roll that is at the end of its life span could be used as test roll. The measured dimensions can be partly validated if the simulated behaviour correlates to the measured behaviour, e.g. thermal bending. The current model can already be used to analyse and explain some special features related to the behaviour of thermo rolls in varying operation conditions.

\section{REFERENCES}

Brierley, P., Hopkins, H. G., Peel, J. D. (1977). Thermal deformations of machine calender rolls, Paper Technology and Industry, Vol. 18, No. 7, 1977, pp. 219-221, ISSN: 0306-252X

Jacot, A.; Maijer, D.; Cockcroft, S. (2000). Modelling of microstructure and residual stress in cast iron calender rolls, Metallurgical and Materials Transactions A: Physical Metallurgy and Materials Science, Vol. 31A, No. 4, 2000, pp. 1201-1211, ISSN: 1073-5623

Maijer, D. M. (1998). Mathematical modelling of microstructure and residual stress evolution in iron calender rolls, A UMI Dissertation, The University of British Columbia, 1998, UMI Co. Dissertation \# NQ38939

Rothenbacher, P., Vomhoff, E. (1985). Mass centering of chilled cast-iron rolls, Tappi Journal, Vol. 68, No. 7, 1985, pp. 82-85, ISSN 0734-1415

Seah, K. H. W., Hemath, J., Sharma, S. C. (1998). Effect of the cooling rate on the dendrite arm spacing and the ultimate tensile strength of cast iron, Journal of material science, Vol. 33, No. 1, 1998, pp. 23-28, ISSN 0022-2461

Wirtz, W. (2002). Advanced thermo rolls for high speed modern calenders, Proceedings of the 7th International Conference on New Available Technologies, June 4-6, 2002, Stockholm, Sweden, p. 5, SPCI

Zaoralek, M. (2004). Higher precision for high temperature calender rolls, Annual Meeting - Technical Section, Canadian Pulp and Paper Association, Preprints, part B, (PAPTAC), Preprint, 2004, pp. 219-223. ISSN: 1494-7722 